\title{
Correction: Significance of major international seaports in the distribution of murine typhus in Taiwan
}

\section{Chi-Chien Kuo, Nicola Wardrop, Chung-Te Chang, Hsi-Chieh Wang, Peter M. Atkinson}

There is an error in reference 55. The correct reference is: Teoh YT, Hii SF, Graves S, Rees R, Stenos J, Traub RJ. Evidence of exposure to Rickettsia felis in Australian patients. One Health. 2016; 2: 95-98.

\section{Reference}

1. Kuo C-C, Wardrop N, Chang C-T, Wang H-C, Atkinson PM (2017) Significance of major international seaports in the distribution of murine typhus in Taiwan. PLoS Negl Trop Dis 11(3): e0005430. https:// doi.org/10.1371/journal.pntd.0005430 PMID: 28264003

Gopenaccess

Citation: Kuo C-C, Wardrop N, Chang C-T, Wang H-C, Atkinson PM (2017) Correction: Significance of major international seaports in the distribution of murine typhus in Taiwan. PLoS Negl Trop Dis 11 (5): e0005589. https://doi.org/10.1371/journal. pntd.0005589

Published: May 3, 2017

Copyright: @ 2017 Kuo et al. This is an open access article distributed under the terms of the Creative Commons Attribution License, which permits unrestricted use, distribution, and reproduction in any medium, provided the original author and source are credited. 